\title{
Application of MM5-CAMx-PSAT Modeling Approach for Investigating Emission Source Contribution to Atmospheric $\mathrm{SO}_{2}$ Pollution in Tangshan, Northern China
}

\author{
Li Li, ${ }^{1,2}$ Shuiyuan Cheng, ${ }^{1}$ Jianbing Li, ${ }^{3}$ Jianlei Lang, ${ }^{1}$ and Dongsheng Chen ${ }^{1}$ \\ ${ }^{1}$ College of Environmental \& Energy Engineering, Beijing University of Technology, Beijing 100124, China \\ ${ }^{2}$ Beijing General Research Institute of Mining \& Metallurgy, Beijing 100070, China \\ ${ }^{3}$ Environmental Engineering Program, University of Northern British Columbia, Prince George, Canada V2N $4 Z 9$ \\ Correspondence should be addressed to Shuiyuan Cheng; bjutpaper@gmail.com
}

Received 19 February 2013; Accepted 13 March 2013

Academic Editor: Guohe Huang

Copyright ( $2013 \mathrm{Li} \mathrm{Li} \mathrm{et} \mathrm{al.} \mathrm{This} \mathrm{is} \mathrm{an} \mathrm{open} \mathrm{access} \mathrm{article} \mathrm{distributed} \mathrm{under} \mathrm{the} \mathrm{Creative} \mathrm{Commons} \mathrm{Attribution} \mathrm{License,} \mathrm{which}$ permits unrestricted use, distribution, and reproduction in any medium, provided the original work is properly cited.

\begin{abstract}
The MM5-CMAx-PSAT modeling approach was presented to identify the variation of emission contribution from each modeling grid to regional and urban air quality per unit emission rate change. The method was applied to a case study in Tangshan Municipality, a typical industrial region in northern China. The variation of emission contribution to the monthly atmospheric $\mathrm{SO}_{2}$ concentrations in Tangshan from each modeling grid of $9 \times 9 \mathrm{~km}$ per $1000 \mathrm{t} / \mathrm{yr}$ of emission rate change was simulated for four representative months in 2006. It was found that the northwestern part of Tangshan region had the maximum contribution variation ratio (i.e., greater than $0.36 \%$ ) to regional air quality, while the lowest contribution variation ratio (i.e., less than $0.3 \%$ ) occurred in the coastal areas. Principal component analysis (PCA), canonical correlation analysis (CCA), and Pearson correlation analysis indicated that there was an obvious negative correlation between the grid-based variation of emission contribution to regional air quality and planetary boundary layer height (PBLH) as well as wind speed, while terrain data presented insignificant impacts on emission contribution variation. The proposed method was also applied to analyze the variation of emission contribution to the urban air quality of Tangshan (i.e., a smaller scale).
\end{abstract}

\section{Introduction}

Air pollution is a serious environmental problem faced by many industrial cities in China as a consequence of many years' rapid economic expansion and insufficient environmental protection measures. It not only poses threats to human health, but also directly affects local economic development [1]. A variety of factors, such as emission sources, land surface characteristics, and meteorological conditions, could affect air pollution simulation. Thus, effective air quality management is usually a challenging task. To tackle such difficulties, it is of crucial importance to quantify the impacts of pollutant emission sources on the air quality of a planning region and understand the corresponding response of atmospheric pollutant concentration to perturbations in pollutant emission rate [2].

Previously, the method of wind rose based on wind speed and direction has been used for qualitatively investigating the impacts of emission sources on regional air quality [3]. Nowadays, computer modeling tools have been recognized as useful means to investigate such impacts [4]. Particularly, there has been a growing interest of applying advanced 3D chemistry-transport models coupled with meteorological models for air quality studies, such as the Model3 Community Multiscale Air Quality (Model-3/CMAQ) $[5,6]$, the Comprehensive Air quality Model with extensions 
(CAMx) [7, 8], the PSU/NCAR mesoscale meteorological model MM5 [9], and the Weather Research and Forecast (WRF) model coupled with Chemistry (WRF-Chem) [10]. For example, Cheng et al. [11] used the coupled MM5ARPS-CMAQ to examine contributions of various emission sources to ambient $\mathrm{PM}_{10}$ concentrations in Beijing, China; Titov et al. [12] applied a MM5-CAMx for predicting $\mathrm{PM}_{10}$ concentrations over the city of Christchurch in New Zealand during critical pollution episodes; Lee et al. [13] employed MM5-CAMx to simulate atmospheric pollutant transport and recirculation in the Santa Claria valley, USA; Shimadera et al. [14] applied MM5-CMAQ to estimate the contribution of transboundary transport of air pollutants from other Asian countries to Japan; Borrego et al. [15] applied MM5CAMx to simulate surface concentrations of ozone and its precursors over the metropolitan area of Porto Alegre, Brazil, and identified the main emission sources of photochemical pollution.

In terms of examining the response of atmospheric pollutant concentration to perturbations in pollutant emission rate, a number of approaches have been proposed in the past years by using various models $[4,11,16,17]$. Particularly, a technique named particulate matter source apportionment technology (PSAT) [18] has been implemented in CAMx to provide source apportionment for primary and secondary particulate matter (PM) species according to emission source categories and their geographic locations [19]. This technique is useful for identifying emission sources that significantly contribute to gaseous or PM pollution. For example, Wagstrom et al. [20] used PSAT to investigate the contribution of power plant $\mathrm{SO}_{2}$ emissions to particulate sulfate concentrations in the Eastern United States, and the results illustrated that PSAT could provide a computationally efficient particulate matter apportionment algorithm to investigate pollutant transport and emission source contributions on regional scales; Koo et al. [21] compared two different methods of investigating relationships between PM concentrations and emission sources and found that PSAT was best at apportioning sulfate, nitrate, and ammonium to sources emitting $\mathrm{SO}_{2}, \mathrm{NO}_{x}$, and $\mathrm{NH}_{3}$, respectively. In addition, there are some other methods to examine emission source apportionment [22-24], which used principal component analysis (PCA) and multilinear regression analysis (MLRA) to identify possible sources of particulate matter (PM) and to determine their contribution to air pollution.

In general, many of the previous source apportionment and emission contribution analysis works focused on examining relationship between the total emission amount of a source from a large-scale planning region and its air pollutant concentration [25]. In fact, for air pollution control strategy development, the more practical question is how pollutant concentrations would respond to emission changes within different small-scale areas of a large planning region [2]. The contribution of emission sources within different small-scale areas to regional and urban air quality could be quite different due to different land surface and meteorological conditions. Thus, it is of critical importance to identify the variation of atmospheric concentration to perturbations in emission rates of small-scale areas within a large planning region.
The priority regulation of emissions with high contribution variation could result in significantly environmental and cost effectiveness. As an extension of our previous efforts, this study was focused on the establishment and application of the MM5-CAMx-PAST modeling approach for examining air quality variation due to perturbation in emission rates from small-scale areas within a large planning region, and it analyzed the possible affected factors. More accurate results can be obtained with the development of the advanced model simulation. The approach and results can provide sound decision making basis for effective air quality management. A case study for Tangshan, a typical industrial region in China, was presented to illustrate the proposed methodology. The MM5-CAMx was used to provide meteorological inputs and to simulate atmospheric $\mathrm{SO}_{2}$ concentrations, and PSAT was applied to investigate the emission contribution variations. An air quality modeling domain with a spatial resolution of 9 by $9 \mathrm{~km}$ was adopted, and the regional and urban air quality variations due to $\mathrm{SO}_{2}$ emission rate perturbation of $1000 \mathrm{t} / \mathrm{yr}$ within each modeling grid were simulated. Principal component analysis (PCA), canonical correlation analysis (CCA), and Pearson correlation analysis methods were then used to analyze the impacts of meteorological variables and terrain data on the emission source contribution variations.

\section{Overview of the Study Area}

Tangshan Municipality, located at about $300 \mathrm{~km}$ east of Beijing, is the biggest industrial center within Hebei province in northern China. It has a total population of 6.9 million in 2000 and a total area of $13,472 \mathrm{~km}^{2}$ including 12 districts as shown in Figure 1. The municipality is situated on the alluvial plain formed by the diluvial sediments from the Yan Mountains in the north. Its mean sea level tends to decrease gradually from its northwest to southeast towards the Bohai Bay. It has a temperate continental climate influenced by wet monsoon, and there is an apparent distinction among four seasons, that is, windy and dry spring, hot and wet summer, mild and clear autumn, and cold and dry winter. The annual average temperature is $10-11.20^{\circ} \mathrm{C}$, and annual average precipitation is about $600 \mathrm{~mm}$. As one of the biggest industrial centers in northern China, Tangshan Municipality has experienced considerable changes through rapid industrialization and urbanization processes in the past decades. However, its growth has also been associated with a number of environmental concerns. Among them, the deteriorated air quality due to a combination of circumstances (i.e., increased energy consumption, population growth, increased industrial emissions, infrastructure construction/expansion, growth of passenger vehicles, and ineffective pollution control measures) posed significant challenges to the public, governments, and industries. Particularly, $\mathrm{SO}_{2}$ pollution has been recognized as an important environmental issue.

\section{Methodology}

3.1. MM5-CAMx-PSAT Modeling. The fifth-generation NCAR/Penn State mesoscale meteorological model (MM5) 

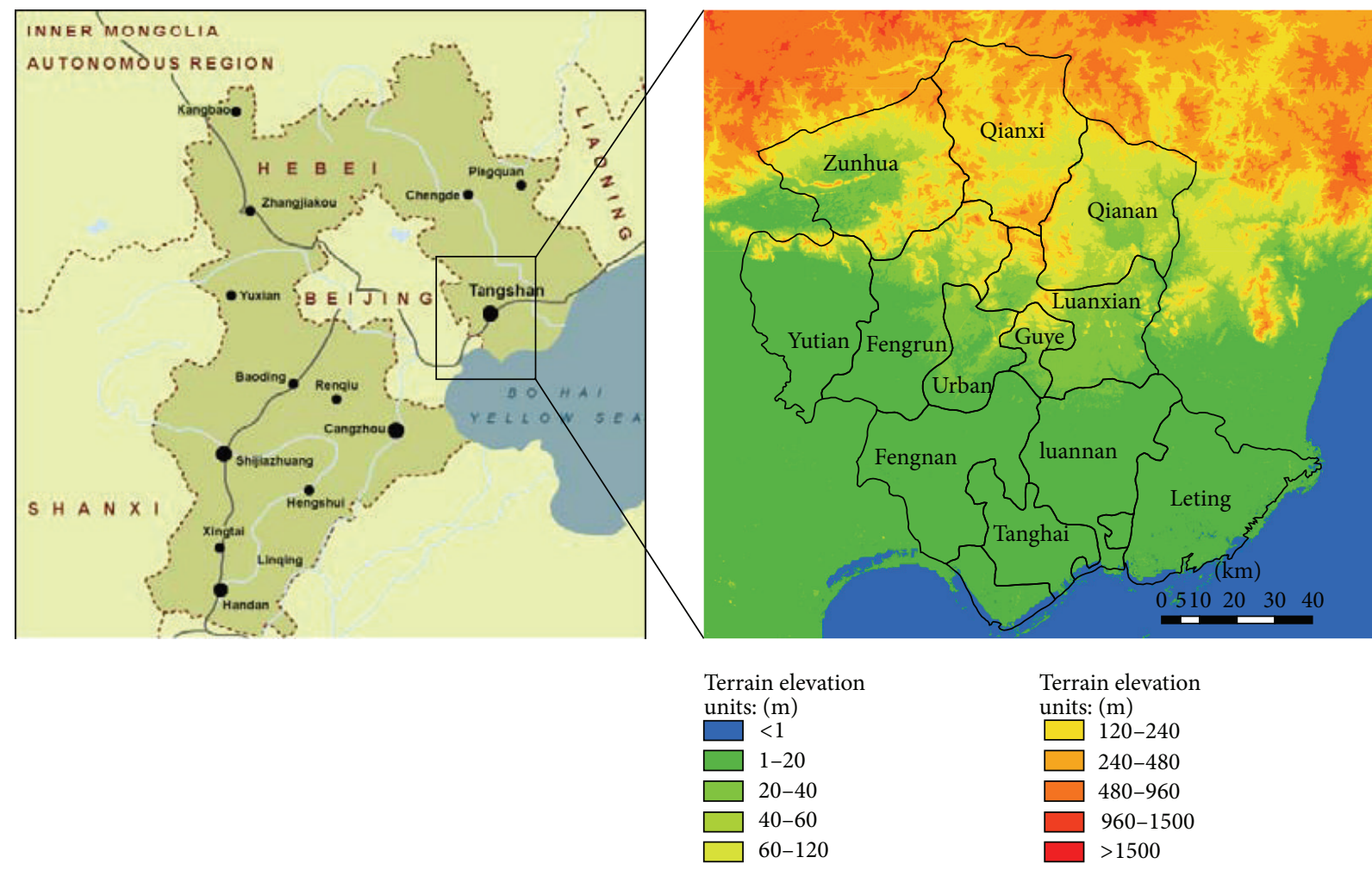

FIGURE 1: Tangshan Municipality and its surrounding cities.

is a limited-area, nonhydrostatic, terrain-following sigmacoordinate model designed to predict meso- and regionalscale atmospheric circulations [9]. It has been frequently used to provide meteorological inputs for many air quality modeling systems [26]. In this study, MM5 (version 3.7) model was applied and configured using two-level nested modeling domains $\left(112-120^{\circ} \mathrm{E}, 37-43^{\circ} \mathrm{N}\right)$ as shown in Figure 2, where domain 1 has a spatial resolution of $27 \mathrm{~km}$ by $27 \mathrm{~km}$ and has been established with a dimension of 60 $\times 60$ grid cells, and domain 2 has a spatial resolution of 9 by $9 \mathrm{~km}$ and has been established with a dimension of $94 \times$ 82 grid cells. Twenty-four full $\sigma$ levels extending from the ground surface to the top of modeling domain (i.e., $200 \mathrm{hpa}$ ) were applied. The 3-D first-guess meteorological fields for modeling were obtained from the Global Tropospheric Analyses datasets provided by the US National Center for Environmental Prediction (NCEP FNL data) and were available with six-hour resolution on a grid of $1^{\circ} \times$ $1^{\circ}$. The four-dimensional data assimilation (FDDA) was implemented using the meteorological observations from surface (eight times a day) and upper air (two times a day) monitoring stations of the Chinese Meteorological Information Comprehensive Analysis and Process System (MICAPS). The following physical parameters schemes in MM5 were selected, including (a) land-use scheme using five-layer LSM, (b) PBL scheme using medium-range forecasts (MRF), (c) cloud microphysics selecting mixedphase, (d) cumulus parameterization schemes selecting

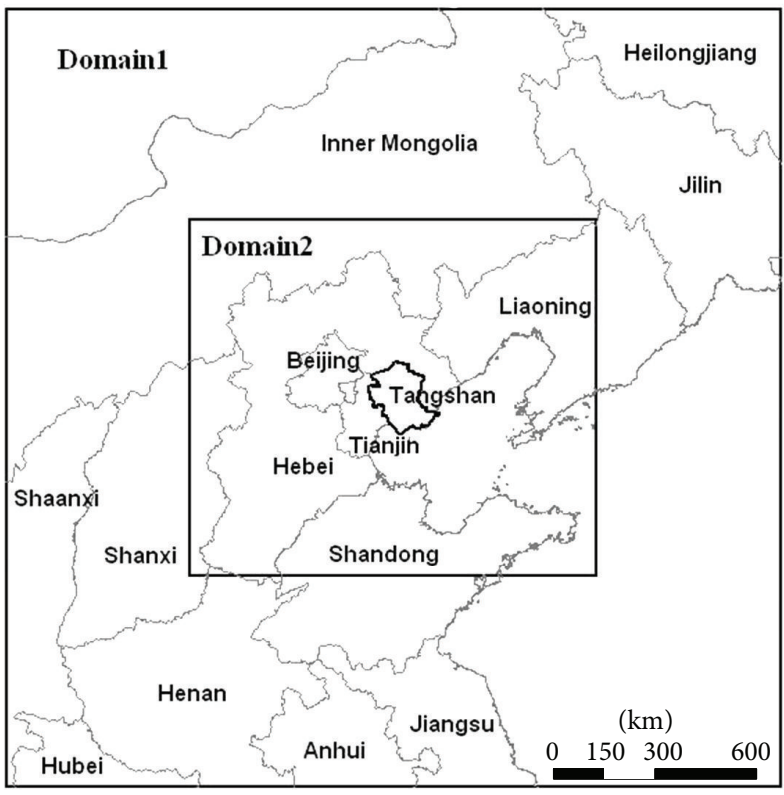

FIgURE 2: Two-level nested modeling domain for MM5.

Grell, and (e) radiation schemes selecting the highly accurate and efficient method (RRTM). The terrain and land-use data were obtained from USGS with a spatial resolution of $30 \mathrm{~s}$. 
The comprehensive air quality model CAMx version 5.1 was used in this study. It is an Eulerian photochemical dispersion model that allows for an integrated assessment of gaseous and particulate air pollutants over many scales ranging from suburban to continental. This model simulates emission, dispersion, chemical reaction, and removal of pollutants in the troposphere by solving the pollutant continuity equation for each chemical species. Its modeling input file formats are compatible with MM5 model. To study the regional emission contributions, the PSAT has been implemented in CAMx to provide $\mathrm{SO}_{2}$ source apportionment among specific geographic regions and source categories [19]. For the simulation of air quality in Tangshan Municipality, CAMx was configured using one modeling domain which was the same as domain 2 of MM5 (Figure 2). Its physical parameters schemes were selected as follows: (a) two-way interactive grid nesting, (b) 12 vertical layers, (c) gas-phase chemistry using CB05 mechanism which includes 156 reactions formulations, and (d) aerosol chemistry using M4/ISORROPIA. In terms of air pollutant emission inventory, it was provided by Tangshan Environmental Protection Agency. The emission inventories of Tangshan's surrounding regions, including Hebei province, Shanxi province, Beijing, Tianjin, and Inner Mongolia, were obtained from the respective environmental protection administrations. The emission inventory of other regions was obtained from Zhang and Streets [27].

The MM5-CAMx was then used to simulate $\mathrm{SO}_{2}$ concentrations in Tangshan for four representative months in 2006, including January, April, July, and October. Two scenarios were selected, including simulating the variation of emission contribution from emission rate perturbation in each modeling grid $(9 \times 9 \mathrm{~km} \mathrm{scale})$ to both regional and urban air quality, represented by the monthly average $\mathrm{SO}_{2}$ concentration of the entire Tangshan region (i.e., largescale receptor 1) and only its urban area (i.e., small-scale receptor 2) (Figure 3), respectively. The modeling procedures include (1) using MM5-CMAx to predict the temporal and spatial distributions of $\mathrm{SO}_{2}$ concentrations within Tangshan Municipality based on its actual emissions in 2006 (i.e., base emission inventory), and the monthly average $\mathrm{SO}_{2}$ concentrations within receptors 1 and 2 were then calculated based on the simulated hourly concentrations, respectively; (2) identifying the contribution variation of each modeling grid to the monthly average $\mathrm{SO}_{2}$ concentrations through adding $1000 \mathrm{t} / \mathrm{yr}$ of $\mathrm{SO}_{2}$ emission (i.e., an arbitrarily selected number) to each grid in addition to the base emission inventory, and the MM5-CMAx was used to predict the temporal and spatial distributions of $\mathrm{SO}_{2}$ concentrations within Tangshan Municipality based on the new emission inventory (base emission inventory plus $1000 \mathrm{t} / \mathrm{yr}$ in a certain grid), and then the monthly average $\mathrm{SO}_{2}$ concentrations within receptors 1 and 2 were calculated, respectively. The difference between the monthly average $\mathrm{SO}_{2}$ concentrations calculated using base inventory and new inventory is regarded as the emission source contribution variation of that grid.

3.2. Multivariate Analysis. The multivariate analysis methods, including PCA and CCA, were used to analyze the impacts of meteorological variables and terrain data on the simulated variation of emission contribution to regional and urban air quality. PCA maximizes the correlation between the original total variance to form new variables that are mutually orthogonal, or uncorrelated. The CCA application was run to investigate possible relationship between these two data sets, especially to establish the maximum correlation among sets of variables. The objective of PCA was to obtain a small number of components that would explain most (i.e., typically above 60\%) of the total variation [28]. In this study, the hourly data of six meteorological variables within MM5, including PBL height (PBLH), temperature at $2 \mathrm{~m}$ above ground (T2), wind speed at $10 \mathrm{~m}$ above ground (WS10), wind direction at $10 \mathrm{~m}$ above ground (WD), sea level pressure (PSLV), and relative humidity $(\mathrm{RH})$, were selected to analyze the principal components of meteorological variables within four representative months in 2006. The objective of CCA was then to investigate possible relationship between the six selected meteorological variables as well as terrain data and the contribution variation of emission within each modeling grid [29].

\section{Results and Discussions}

4.1. Modeling Performance. The performance of the MM5CAMx was evaluated using scatter plots [30]. The groundbased $\mathrm{SO}_{2}$ observation results from three air quality monitoring stations located within Tangshan urban ("Urban" is showed in Figure 1) were averaged and were then compared with the predicted daily $\mathrm{SO}_{2}$ concentration of the Tangshan urban area in the four selected months in 2006. Figure 4 displays the comparison results. The $y=x$ line on the scatter plots represents perfect agreement between the two data sets. A pair value above the $y=x$ line indicates a situation of overprediction, while the pair value below the line indicates underprediction. In general, Figure 4 shows that most of the scatter plots are adjacently distributed on both sides of $y=x$ line, which does highlight a consistent over- and underprediction for $\mathrm{SO}_{2}$ concentration using the modeling system. Considering the inherent uncertain nature associated with meteorological parameters and air quality prediction, this fluctuation still indicates that the accuracy of model prediction is reasonable. In fact, the correlation coefficients between simulated and observed data were calculated as 0.781, 0.621, 0.690, and 0.801 for January, April, July, and October, respectively. Thus the performance of the coupled modeling system is satisfactory and acceptable [4].

\subsection{Simulated $\mathrm{SO}_{2}$ Concentration Distribution Using Base} Emission Inventory. In the year of 2006, Tangshan Municipality had a total of 598 industrial establishments, including electrical, metallurgical, mining, chemical, construction materials, and textile industries. Spatial distributions and emission rates of $\mathrm{SO}_{2}$ from these sources were investigated and shown in Figure 5(a). The hourly $\mathrm{SO}_{2}$ concentrations in January 2006 in the entire Tangshan region were simulated using MM5-CAMx, and their corresponding monthly averages were then calculated. Figure 5(b) displays the simulated 


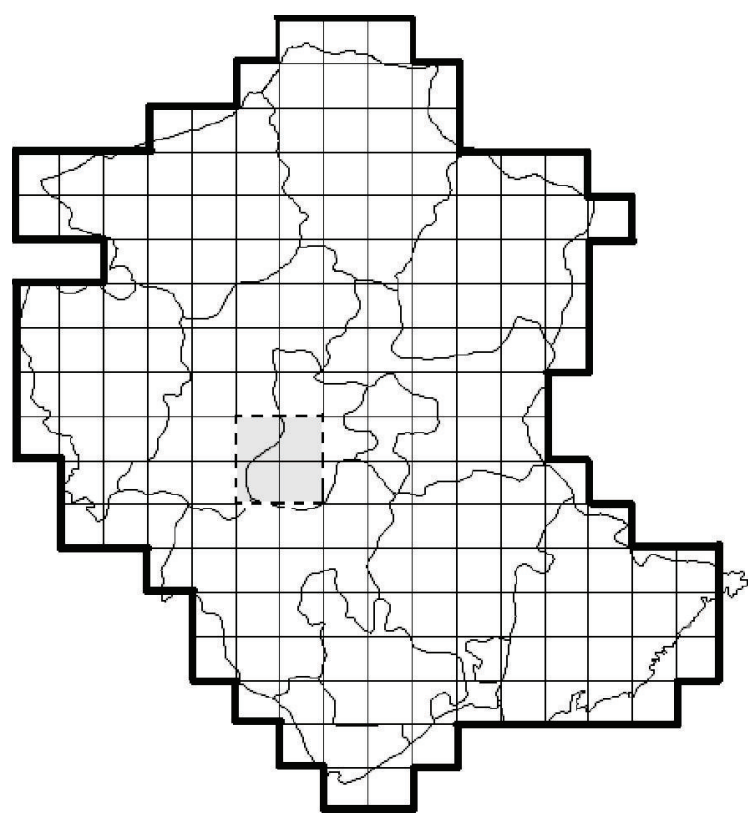

$\begin{array}{ll}\square & \text { Receptor } 1 \\ L_{--1} & \text { Receptor } 2\end{array}$

FIGURE 3: Schematic of modeling scenarios showing receptors 1 and 2.

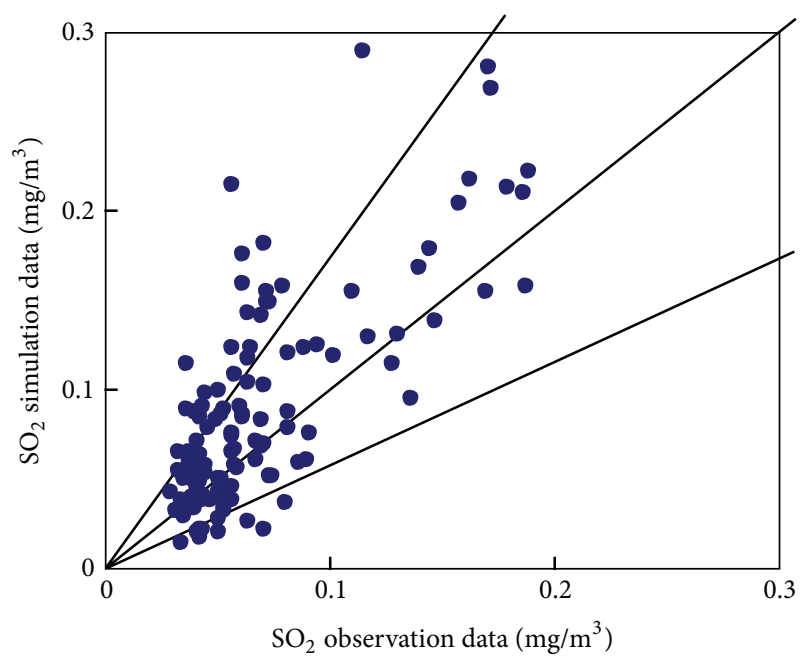

Figure 4: Comparison between observed and predicted $\mathrm{SO}_{2}$ concentrations (daily average value of January, April, July, and October 2006).

$\mathrm{SO}_{2}$ concentration in Tangshan region in January 2006, and it illustrates that $\mathrm{SO}_{2}$ pollutions occurred in most areas of Tangshan region due to pollutant emissions and unfavorable meteorological conditions. In general, the air quality in Tangshan region was not satisfactory, and the municipal government and industries need to take actions to improve such situation. For cost-effective air quality management in Tangshan, the identification of the variation of emission source contribution to the regional and urban air quality due to emission perturbation in each small-scale emission area is of fundamental importance. Such information could provide sound basis for identifying emission areas requiring priority regulation.

4.3. Variation of Seasonal Emission Source Contribution to Regional Air Quality. The variation of emission contribution to the receptor 1 (shown in Figure 3) air quality due to $\mathrm{SO}_{2}$ emission perturbation of $1000 \mathrm{t} / \mathrm{yr}$ of each modeling grid was calculated at first for the four representative months in 2006 using the MM5-CAMx-PSAT. Then, the corresponding monthly arithmetic averages were plotted using Geographic Information System (GIS) interpolation method. Figure 6 presents the spatial distribution of the variation of emission contribution to regional monthly $\mathrm{SO}_{2}$ concentration in Tangshan. It is observed from Figure 6(a) that emissions in the junction of Yutian and Zunhua Counties had the maximum variation of emission contribution to air pollution in receptor 1 , with more than $52 \mu \mathrm{g} / \mathrm{m}^{3}$ of variation per $1000 \mathrm{t} / \mathrm{yr}$ of $\mathrm{SO}_{2}$ emission per $9 \times 9 \mathrm{~km}$ modeling grid in January, while emissions from the coastal areas of the southeast of Tangshan had the minimum variation of emission contribution (i.e., less than $35 \mu \mathrm{g} / \mathrm{m}^{3}$ of variation per $1000 \mathrm{t} / \mathrm{yr}$ of $\mathrm{SO}_{2}$ emission per modeling grid of $9 \times 9 \mathrm{~km})$. It can also be found that the grid-based variation of emission contribution to $\mathrm{SO}_{2}$ pollution tended to gradually decrease from the northwest to southeast of Tangshan Municipality in January. In April, as shown in Figure 6(b), emissions from the southeast of Qianan County and the southern coastal areas of Tangshan displayed the maximum variations of contribution to $\mathrm{SO}_{2}$ pollution in receptor 1 , with more than $13.9 \mu \mathrm{g} / \mathrm{m}^{3}$ of contribution variation per $1000 \mathrm{t} / \mathrm{yr}$ of $\mathrm{SO}_{2}$ emission per grid. Meanwhile, emissions from the eastern area of Leting and northern part of Qianxi County showed minimum contribution variations. In terms of July, as shown in Figure 6(c), emissions from the coastal areas of Tangshan made the largest contribution variations (i.e., greater than $14.6 \mu \mathrm{g} / \mathrm{m}^{3}$ of variation per $1000 \mathrm{t} / \mathrm{yr}$ of $\mathrm{SO}_{2}$ emission per grid), while the spatial distribution of emission contribution variations showed several local high-value points, and the minimum contribution variation occurred in Qianxi County. It is shown in Figure 6(d) that the variation of emission contributions to the average $\mathrm{SO}_{2}$ concentration in receptor 1 in October displayed a relatively even distribution, tending to gradually decrease from the high-value area of Yutian County (i.e., with contribution variation of greater than $26.0 \mu \mathrm{g} / \mathrm{m}^{3}$ ) to the east and southeast of Tangshan. Consequently, the simulation results indicate that the largest variations of emission contribution to air pollution occurred in January, and the contribution variation distribution displayed an apparent seasonal difference. This is due to the fact that Tangshan has the temperate continental climate, and different meteorological conditions among four seasons would cause such seasonal differences. tribution Variation. PCA was used to identify the principal 


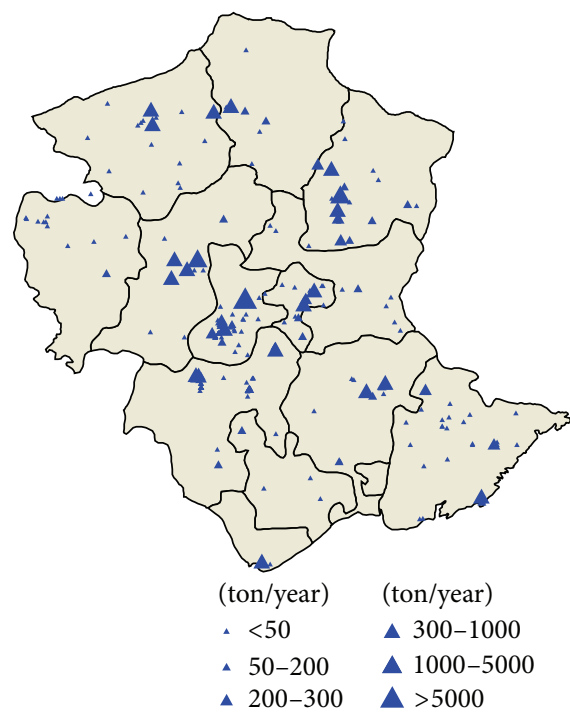

(a)

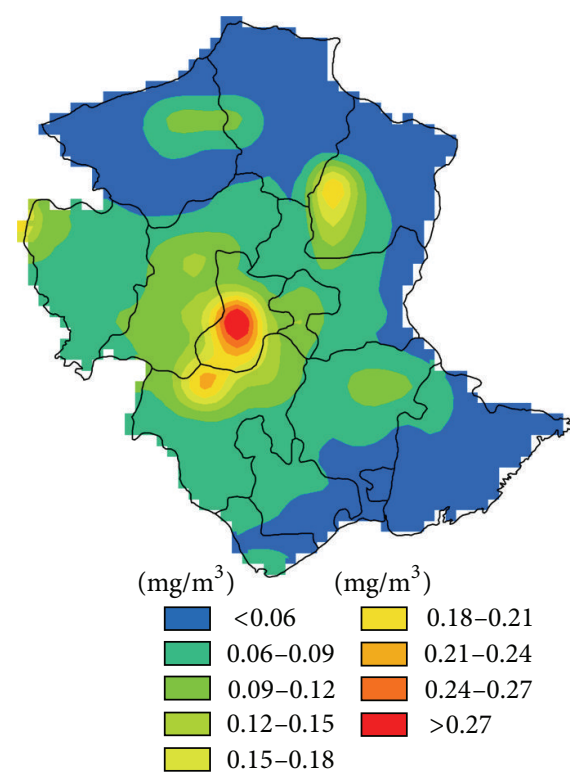

(b)

Figure 5: Annual emission rate of $\mathrm{SO}_{2}$ and simulated monthly $\mathrm{SO}_{2}$ concentration in January 2006: (a) emission rate; (b) concentration distribution.

components from six meteorological variables in Tangshan. Table 1 lists the PCA results for January, April, July, and October 2006, respectively, and the eigenvalues of PCA for the meteorological variables are also presented. It is found from Table 1 that examination of 30-day data for each modeling grid in January led to three principal components accounting for $81.8 \%$ of the total variance. Using the values of the respective principal component loadings presented in Table 1 , there is a reasonable interpretation for these components. Only loadings with absolute values greater than $50 \%$ were selected for PC interpretation [31]. The first PC was PBL height (with component loadings of -0.503), and the second PCs showed that a main source of variation was wind speed (with component loadings of 0.529) and temperature (with component loadings of 0.598 ), while the third PC was wind direction (with component loadings of 0.801). Thus, the PCA results for January indicated low PBL height and prevalent northwest winds as well as inversion weather. These meteorological conditions could result in higher atmospheric stability in surface layer in Tangshan which then facilitated the accumulation of pollutants near the ground, leading to the highest variation of emission contributions to regional air quality from the modeling grids as compared to other months (Figure 6(a)). In terms of meteorological conditions in April, Table 1 illustrates that the first PCs were PBL height (with component loadings of 0.574 ) and relative humidity (with component loadings of -0.515). The second PCs were temperature (with component loadings of 0.715 ) and sea level pressure (with component loadings of -0.603), while the third PC was wind speed (with component loadings of 0.723 ). The PCA results for April indicate a dry spring with high PBLH, high temperature, low sea level pressure, and strong wind, and such meteorological conditions were conducive for dispersion of pollutants, leading to relatively low variation of emission contribution to regional air quality from modeling grids (Figure 6(b)). For meteorological conditions in July, the PCA results illustrate that the first PCs were PBL height (with component loadings of 0.603 ) and relative humidity (with component loadings of 0.549 ), and the second PC was wind direction (with component loadings of -0.698), while the third PC was wind speed (with component loadings of -0.832 ). The PCA results indicate a wet and rainy summer with high PBL height and prevalent southeast winds influenced by the maritime climate. Such meteorological conditions would help disperse and reduce pollutant concentrations, leading to minimum variation of emission contribution to regional air quality in July as compared to other months (Figure 6(c)). For October, the PCA results showed a mild and clear autumn, with first PCs being the temperature (with component loading of 0.52) and sea level pressure (with component loading of -0.576), the second PCs being PBLH (with component loading of 0.684 ) and wind speed (with component loading of 0.649), and the third PC being relative humidity (with component loading of -0.696). These values illustrate that the temperature in autumn was slightly higher than that in spring, wind was not stronger than that in spring, and the prevalently northwest wind was influenced by the invasion of cold air. Due to the impact of such meteorological conditions, the variation of emission contribution to regional air quality in October from modeling grids was between the minimum and maximum (Figure 6(d)).

Results of CCA between grid-based variation of emission contribution to regional air quality and meteorology-terrain data in Tangshan are presented in Table 2. In this study, there was only one canonical variable $(\mathrm{CV})$. The correlations of 


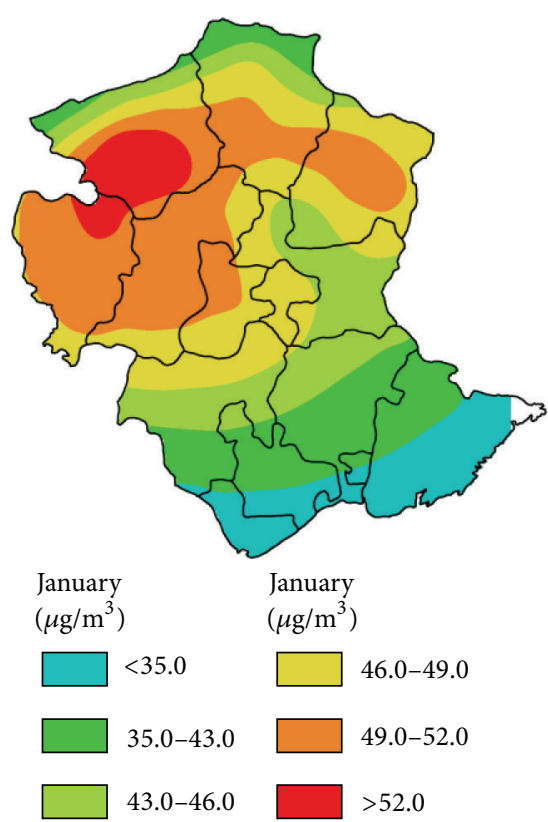

(a)
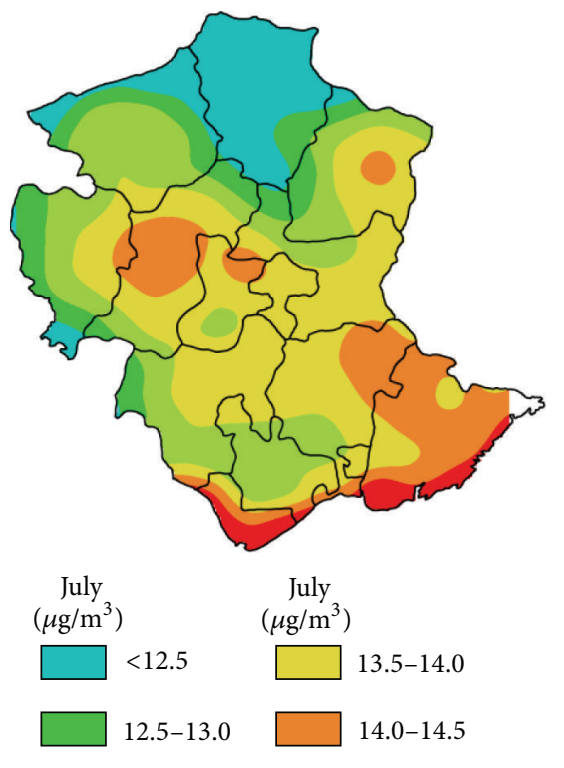

$13.0-13.5 \quad \square>14.5$

(c)
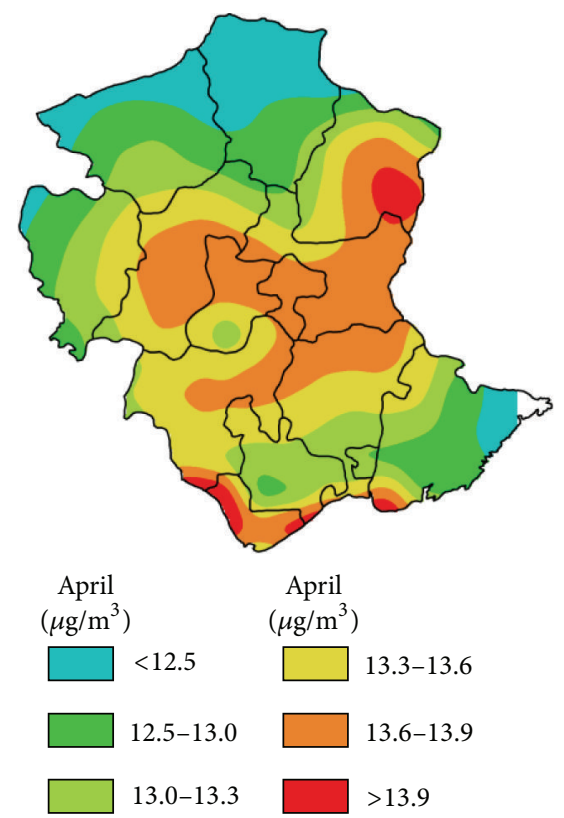

(b)
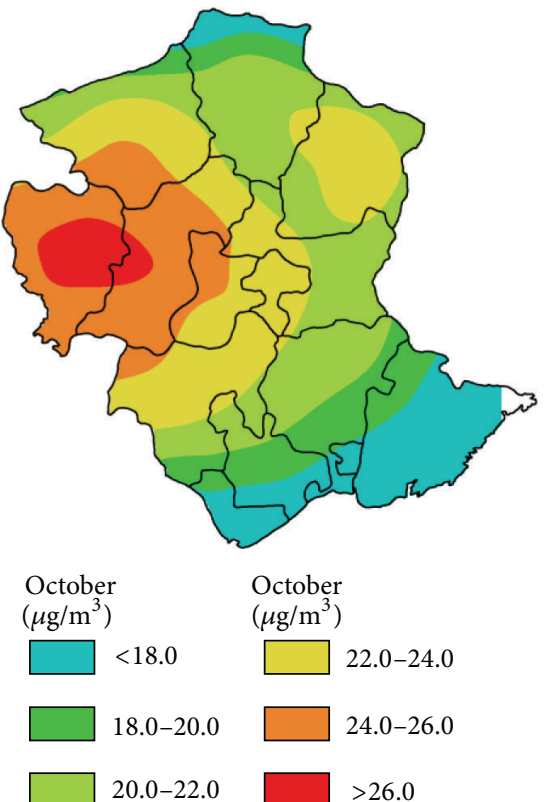

(d)

FIGURE 6: Simulated monthly average emission contribution response to regional average $\mathrm{SO}_{2}$ concentration (i.e., receptor 1) due to $\mathrm{SO}_{2}$ emission perturbation of $1000 \mathrm{t} / \mathrm{yr}$.

CV1 were $0.781,0.748,0.725$, and 0.807 for the four selected months, respectively, and all CCAs passed the statistical test of significance. According to the variable loading values shown in Table 2, the main meteorological variables were PBL height and wind speed in January which showed a negative correlation with grid-based variation of emission contribution to air quality in receptor 1 . Pearson correlation analysis also gave the same results as CCA. Figure 7 presents the monthly average PBLH and WS10 in January, and the contours exhibit negative correlation with Figure 6(a). This indicates that high variation of emission contribution was related to low PBL height and low wind speed conditions. It is found from Table 2 that the variable loading values for April and October gave similar results for January. However, CCA and Pearson correlation analysis gave different results for July. The CCA results showed that relative humidity was associated 
TABLE 1: PCA results for meteorological variables in four selected months in 2006.

\begin{tabular}{|c|c|c|c|c|c|c|c|c|}
\hline \multirow{2}{*}{ PC } & \multirow{2}{*}{ Eigenvalue } & \multirow{2}{*}{ Proportion variance } & \multirow{2}{*}{ Cumulative proportion } & \multirow{2}{*}{ Variable } & \multicolumn{4}{|c|}{ Principal component loadings } \\
\hline & & & & & $\mathrm{PC} 1$ & $\mathrm{PC} 2$ & PC3 & PC4 \\
\hline \multicolumn{9}{|c|}{ (a) January } \\
\hline $\mathrm{PCl}$ & 1.492 & 0.371 & 0.371 & PBLH & -0.503 & 0.421 & -0.209 & 0.000 \\
\hline PC2 & 1.279 & 0.273 & 0.644 & $\mathrm{~T} 2 \mathrm{~m}$ & 0.326 & 0.598 & 0.000 & -0.26 \\
\hline PC3 & 1.022 & 0.174 & 0.818 & WS10 & -0.411 & 0.529 & -0.132 & 0.28 \\
\hline PC4 & 0.772 & 0.099 & 0.918 & PSLV & -0.391 & -0.405 & -0.488 & 0.21 \\
\hline PC5 & 0.554 & 0.051 & 0.969 & $\mathrm{RH}$ & 0.479 & 0.147 & -0.244 & 0.799 \\
\hline PC6 & 0.433 & 0.031 & 1.000 & WD & -0.297 & 0.000 & 0.801 & 0.412 \\
\hline \multicolumn{9}{|c|}{ (b) April } \\
\hline $\mathrm{PC1}$ & 1.516 & 0.383 & 0.383 & PBLH & 0.574 & 0.207 & -0.143 & 0.000 \\
\hline PC2 & 1.280 & 0.273 & 0.656 & $\mathrm{~T} 2 \mathrm{~m}$ & -0.106 & 0.715 & -0.215 & 0.000 \\
\hline PC3 & 0.982 & 0.161 & 0.817 & WS10 & 0.318 & 0.171 & 0.723 & -0.56 \\
\hline PC4 & 0.813 & 0.110 & 0.927 & PSLV & 0.294 & -0.603 & -0.305 & -0.23 \\
\hline PC5 & 0.523 & 0.046 & 0.973 & RH & -0.515 & -0.22 & 0.453 & 0.227 \\
\hline PC6 & 0.405 & 0.027 & 1.000 & WD & 0.455 & 0.000 & 0.336 & 0.758 \\
\hline \multicolumn{9}{|c|}{ (c) July } \\
\hline $\mathrm{PCl}$ & 1.435 & 0.343 & 0.343 & PBLH & 0.603 & -0.242 & 0.000 & -0.141 \\
\hline PC2 & 1.182 & 0.233 & 0.576 & $\mathrm{~T} 2 \mathrm{~m}$ & 0.484 & 0.337 & -0.207 & -0.465 \\
\hline PC3 & 1.056 & 0.186 & 0.762 & WS10 & -0.137 & -0.171 & -0.832 & -0.33 \\
\hline PC4 & 0.785 & 0.103 & 0.865 & PSLV & -0.279 & -0.497 & 0.404 & -0.71 \\
\hline PC5 & 0.729 & 0.089 & 0.953 & $\mathrm{RH}$ & 0.549 & 0.255 & -0.188 & 0.000 \\
\hline PC6 & 0.529 & 0.047 & 1.000 & WD & 0.000 & -0.698 & -0.257 & 0.381 \\
\hline \multicolumn{9}{|c|}{ (d) October } \\
\hline $\mathrm{PCl}$ & 1.535 & 0.392 & 0.392 & PBLH & -0.134 & 0.684 & -0.127 & 0.000 \\
\hline PC2 & 1.324 & 0.292 & 0.685 & $\mathrm{~T} 2 \mathrm{~m}$ & 0.52 & 0.301 & 0.397 & 0.000 \\
\hline PC3 & 0.951 & 0.151 & 0.835 & WS10 & -0.226 & 0.649 & -0.132 & 0.000 \\
\hline PC4 & 0.785 & 0.103 & 0.938 & PSLV & -0.576 & -0.138 & -0.352 & -0.13 \\
\hline PC5 & 0.498 & 0.041 & 0.979 & RH & 0.376 & 0.000 & -0.696 & 0.607 \\
\hline PC6 & 0.351 & 0.021 & 1.000 & WD & -0.433 & 0.000 & 0.448 & 0.781 \\
\hline
\end{tabular}

with the second highest absolute loading value (i.e., -0.715 ) which indicated an obvious negative correlation between humidity and grid-based variation of emission contribution. However, the Pearson correlation value for $\mathrm{RH}$ was just -0.066 . Since it is widely recognized that wet deposition has the function of removing pollutant, the results of CCA seemed more reasonable to find the relationship between more than two variables. The terrain data did not show obvious correlation with grid-based emission contribution variation through CCA and Pearson correlation analysis. This can be explained by the fact that most areas of Tangshan are flat although it is located in the alluvial plains of the Yanshan Mountains, with higher elevation in the northwestern part and lower elevation in the southeastern region.

4.5. Variation of Annual Emission Contribution to Regional Air Quality. The modeling results (Figure 6) indicated significant seasonal change of emission contribution variation for each modeling grid due to the impacts of many meteorological factors such as PBL height and wind speed. Thus, a parameter of emission contribution variation ratio was introduced in this study for investigating the variation of annual average emission contribution to regional air quality for the convenience of air quality management. The calculation of emission contribution variation ratio is as follows:

$$
R_{i}=\frac{1}{4}\left|\sum \frac{C_{i, j}}{\sum_{i=1}^{n} C_{i, j}}\right|,
$$

where $C_{i, j}$ is the variation of emission contribution to the monthly average $\mathrm{SO}_{2}$ concentration of the receptor area in month $j$ (i.e., January, April, July, and October) per 1000 t/yr of emission rate change in grid $i\left(\mu \mathrm{g} / \mathrm{m}^{3}\right) ; R_{i}$ is the annual average emission contribution variation ratio of grid $i$ due to $1000 \mathrm{t} / \mathrm{yr}$ of emission rate change; $n$ is the total number of modeling grids. Figure 8(a) presents the annual emission contribution variation ratio of each grid to average $\mathrm{SO}_{2}$ concentration in receptor 1 in 2006. It is found that the northwestern part of Tangshan such as the junction area of Yutian and Fengrun Counties had the maximum emission contribution variation ratio (i.e., greater than $0.36 \%$ ) to the air quality of receptor 1 , indicating that the regional air quality was more sensitive to the emissions from the northwestern part of Tangshan. The contribution variation ratio tended to decrease towards the north and southeast of Tangshan, while 


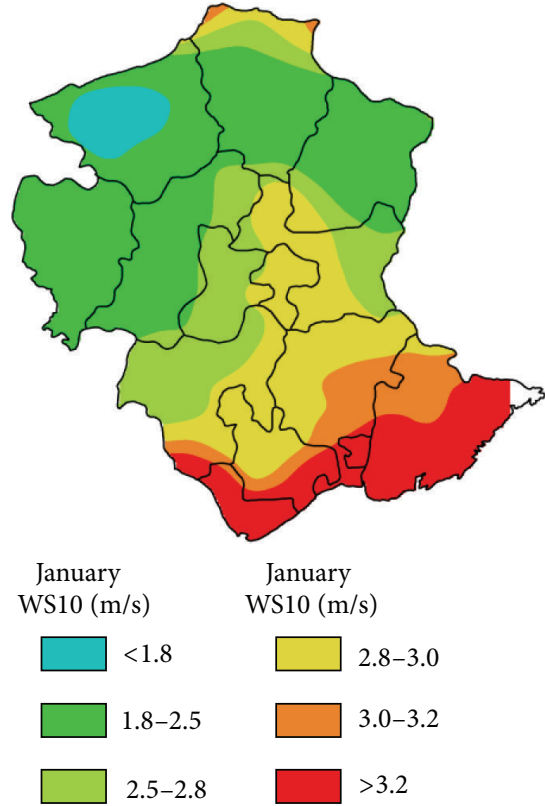

(a)

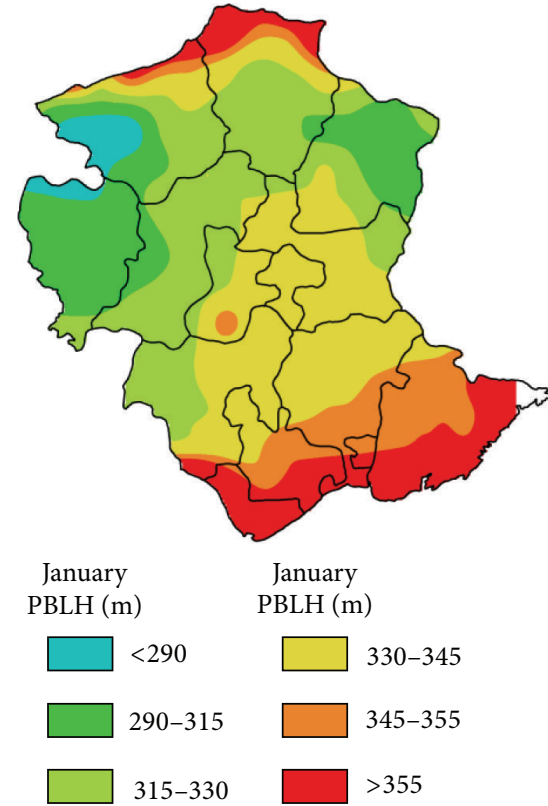

(b)

FIGURE 7: Monthly average wind speed at $10 \mathrm{~m}$ above ground (WS10) (a) and planetary boundary layer height (PBLH) (b) in January 2006.

TABLE 2: Results of CCA between grid-based variation of emission contribution to air quality in receptor 1 and meteorological/terrain data in Tangshan, 2006.

\begin{tabular}{|c|c|c|c|c|c|}
\hline \multicolumn{3}{|c|}{ (a) January } & \multicolumn{3}{|c|}{ (b) April } \\
\hline $\mathrm{CV}$ & Correlation & Pearson & $\mathrm{CV}$ & Correlation & Pearson \\
\hline CV1 & 0.781 & Correlation & CV1 & 0.748 & Correlation \\
\hline Variable & Loadings & & Variable & Loadings & \\
\hline Contribution & 0.987 & 1.000 & Contribution & 0.987 & 1.000 \\
\hline PBLH & -0.439 & -0.677 & PBLH & -0.639 & -0.483 \\
\hline $\mathrm{T} 2 \mathrm{~m}$ & -0.062 & -0.163 & $\mathrm{~T} 2 \mathrm{~m}$ & -0.387 & -0.188 \\
\hline WS10 & -0.626 & -0.746 & WS10 & -0.672 & -0.588 \\
\hline TERRAIN & 0.009 & 0.041 & TERRAIN & -0.039 & 0.242 \\
\hline PSLV & 0.061 & -0.002 & PSLV & -0.038 & 0.205 \\
\hline $\mathrm{RH}$ & -0.160 & 0.094 & RH & -0.479 & 0.221 \\
\hline WD & -0.069 & -0.150 & WD & -0.011 & -0.243 \\
\hline \multicolumn{3}{|c|}{ (c) July } & \multicolumn{3}{|c|}{ (d) October } \\
\hline $\mathrm{CV}$ & Correlation & Pearson & $\mathrm{CV}$ & Correlation & Pearson \\
\hline CV1 & 0.725 & Correlation & CV1 & 0.807 & Correlation \\
\hline Variable & Loadings & & Variable & Loadings & \\
\hline Contribution & 0.987 & 1.000 & Contribution & 0.987 & 1.000 \\
\hline PBLH & -0.989 & -0.416 & PBLH & -0.434 & -0.724 \\
\hline $\mathrm{T} 2 \mathrm{~m}$ & -0.061 & -0.167 & $\mathrm{~T} 2 \mathrm{~m}$ & -0.088 & -0.113 \\
\hline WS10 & -0.502 & -0.347 & WS10 & -0.591 & -0.729 \\
\hline TERRAIN & -0.005 & 0.346 & TERRAIN & -0.003 & 0.045 \\
\hline PSLV & -0.050 & 0.029 & PSLV & 0.010 & -0.001 \\
\hline $\mathrm{RH}$ & -0.715 & -0.066 & $\mathrm{RH}$ & -0.120 & 0.029 \\
\hline WD & 0.091 & -0.086 & WD & 0.010 & -0.035 \\
\hline
\end{tabular}


some local higher values occurred within Qianan County. The lowest emission contribution variation ratio (i.e., less than $0.3 \%$ ) occurred in the coastal areas of Tangshan and the northern part of Qianxi County, implying that the regional air quality was less sensitive to the emissions from these areas. As a result, in order to improve regional air quality, the industries (Figure 5(a)) located within the more sensitive areas (i.e., northwestern part of Tangshan) should reduce their emissions or be relocated to the less sensitive areas such as the coastal area of Tangshan Municipality.

As described earlier, CCA indicated that a negative correlation existed between wind speed and grid-based emission contribution variation. This can be proved from another perspective. The data from three state-controlled weather stations located in Zunhua (northwestern area), Tangshan urban (center area), and Leting (southeastern area) (Figure 1) were used for meteorological factor analysis. The monthly average wind speed and calm frequency were previously identified as the main meteorological factors affecting air pollution [25] and thus were used for analysis in this study. Table 3 lists the average wind speed and calm frequency of the four representative months in 2006. Previous studies suggested that the greater the wind speed and the smaller the calm frequency, the more beneficial for pollutant dispersion. It can be observed from Table 3 that the ranking of monthly and yearly average wind speed from large to small is Leting, Tangshan urban, and Zunhua. This would indicate that the dispersion capability of pollutants gradually decreases from the coast (i.e., Leting) to inland area (i.e., Zunhua), leading to gradually increased emission contribution variation from the coastal area to inland area as shown in Figure 8(a). However, the order of calm frequency for the three selected areas does not hold the same as that of average wind speed. Although the calm frequency in Zunhua area was higher than that in other two areas in all seasons which was less conducive to the dispersion of pollutants, the calm frequencies in Tanghan urban area in April and July were significantly lower than those in Leting, which could give a good explanation for the local low emission contribution variation values shown in the center area of Tangshan in Figures 6(b) and 6(c). In addition, Figure 8 (a) not only displays the annual average emission contribution variation ratios of the modeling grids to air quality in the entire Tangshan region, but also gives a visual representation of the dominant wind direction. It is found from Figure 8(a) that the east-west direction modeling grids had higher contribution variation ratios than north-south direction girds, implying that east-west was the dominant wind direction in Tangshan Municipality.

4.6. Variation of Annual Emission Contribution to Urban Air Quality. Air quality control within a smaller area than regional scale is usually important and more practical in urban environmental management. In this study, the urban area of Tangshan was selected as a control area (i.e., receptor 2 ), and the grid-based variation of emission contribution to the average air quality of receptor 2 was then simulated using MM5-CAMx-PSAT. Figure 8(b) shows the distribution of grid-based annual emission contribution variation ratio.
TABLE 3: Wind speed and calm wind frequency in Tangshan in 2006.

\begin{tabular}{lccc}
\hline Area & Month & Wind speed $(\mathrm{m} / \mathrm{s})$ & Calm frequency $(\%)$ \\
\hline \multirow{4}{*}{ Zunhua } & January & 1.49 & 5.71 \\
& April & 2.61 & 3.00 \\
& July & 1.66 & 4.12 \\
& October & 1.43 & 11.07 \\
& Annual & 1.80 & 6.01 \\
\hline \multirow{4}{*}{ Tangshan } & January & 1.91 & 1.22 \\
urban & April & 2.63 & 0.43 \\
& July & 1.91 & 0.82 \\
& October & 1.77 & 7.79 \\
& Annual & 2.06 & 2.59 \\
\hline \multirow{4}{*}{ Leting } & January & 2.09 & 3.67 \\
& April & 3.03 & 2.14 \\
& July & 2.08 & 1.23 \\
& October & 1.86 & 4.51 \\
& Annual & 2.27 & 2.90 \\
\hline
\end{tabular}

It is found that the grids with largest contribution variation ratios were receptor 2 itself (with contribution variation ratio of greater than $10.0 \%$ ), and the second were the grids mainly surrounding receptor 2 . Figure 8 (b) also reveals that emission contribution variation ratio had correlation with the distance between emission grids and the receptor area. The eastwest modeling grids around receptor 2 had slightly higher emission contribution variation ratio than the north-south grids. This could be explained by the fact that east and west winds were the main wind directions in the study area as observed from the monitoring data in 2006. The contribution variation ratios of the remaining parts of Tangshan Municipality were very small, with minimum contribution variation ratios occurring in the coastal areas and northern parts of Tangshan (i.e., less than $0.2 \%$ ). The results indicated that the receptor itself as emission grids had significant contribution to the urban air quality. The obtained emission contribution variation analysis results are of practical importance for air quality management. For example, to improve the urban air quality in Tangshan, the industries (Figure 5(a)) within the more sensitive areas (i.e., Tangshan urban, Fengrun, and Fengnan) should be relocated to the less sensitive areas (i.e., coastal area of Tangshan), and the new industrial projects with $\mathrm{SO}_{2}$ emissions such as power plants should also be located within the less sensitive coastal areas.

\section{Conclusions}

A modeling grid-based emission contribution analysis approach was proposed to identify emission areas with higher response of regional and urban air quality change due to emission rate perturbation. This approach relied on a coupled MM5-CAMx where MM5 was used to provide meteorological inputs for the air quality model CAMx, while CAMx was used to predict air pollutant concentration distributions. The particulate matter source apportioning 


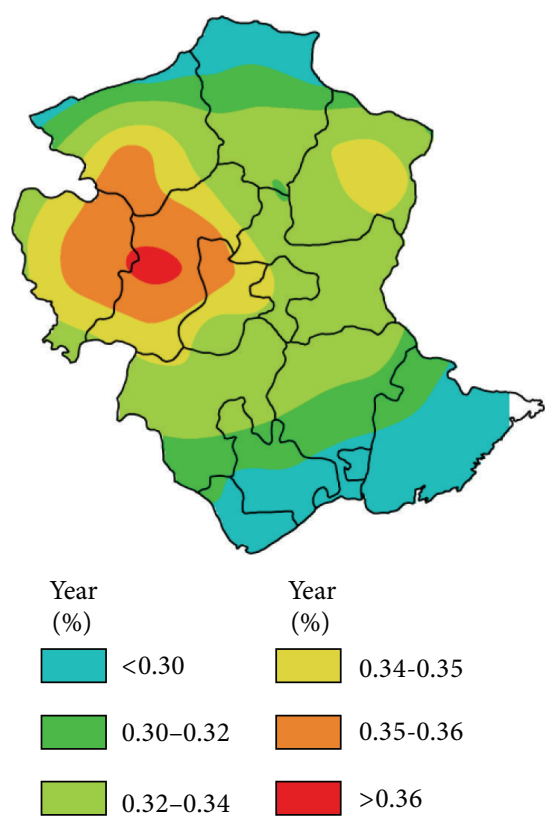

(a)

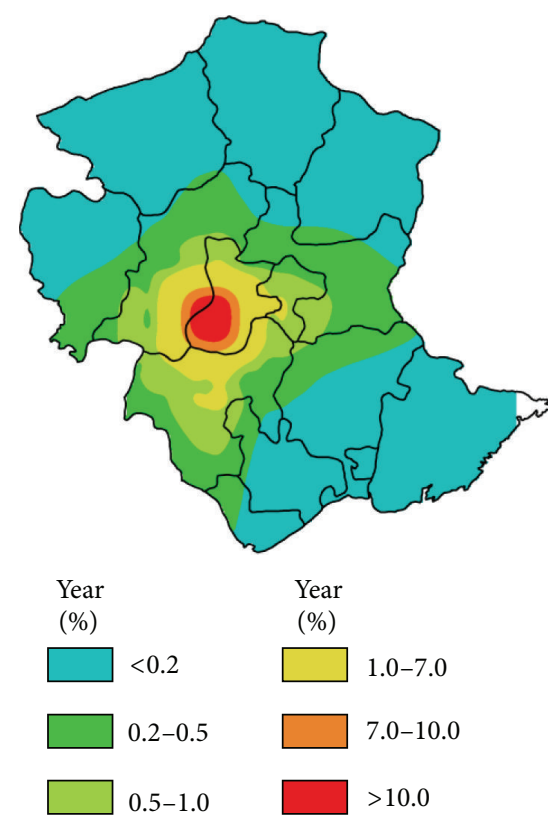

(b)

FIGURE 8: Distribution of annual average emission contribution variation ratio of modeling grids to air quality in (a) receptor 1 and (b) receptor 2 .

technology (PSAT) within CAMx was used to calculate the variation of emission contribution to air quality from emission rate perturbation within each modeling grid. The method was applied to a case study in Tangshan Municipality in northern China. The MM5-CMAx was implemented to predict hourly $\mathrm{SO}_{2}$ concentrations based on the base emission inventory of $\mathrm{SO}_{2}$ in 2006 with modeling grid scale of $9 \times 9 \mathrm{~km}$, and the impact of emission perturbation in each modeling grid to atmospheric $\mathrm{SO}_{2}$ concentrations was calculated by using PSAT technology through adding $1000 \mathrm{t} / \mathrm{yr}$ of $\mathrm{SO}_{2}$ emission to the grid in addition to the base emission inventory. The variation of emission contribution to regional air quality from each modeling grid per $1000 \mathrm{t} / \mathrm{yr}$ of emission rate change was obtained for four representative months (January, April, July, and October) in 2006. PCA and CCA were conducted to examine the impacts of meteorological factors on the variation of emission source contribution, and the results indicated that there was an obvious negative correlation between emission contribution variation and planetary boundary layer height (PBLH) as well as wind speed. The analysis of the variation of emission contribution to annual regional $\mathrm{SO}_{2}$ concentration (i.e., larger scale) indicated that the northwestern part of Tangshan was the most sensitive area with emission contribution variation ratio of more than $0.36 \%$, while the southern coastal area had the lowest contribution variation ratio of less than $0.30 \%$. The proposed method was also applied to analyze the variation of emission contribution to the $\mathrm{SO}_{2}$ pollution in the urban area in Tangshan (i.e., at a smaller scale), and it was found that the largest contribution grids were the urban area itself (with contribution variation ratio of greater than $10.0 \%$ ), and the minimum contribution variation ratios (i.e., less than $0.2 \%$ ) occurred in the coastal areas and northern parts of Tangshan. Based on the modeling results, the emission sources within the areas with higher contribution variation ratios should be regulated with priority or relocated to other areas with lower contribution variation ratios such as the coastal areas in Tangshan. In summary, the proposed methodology can be applied to address many other regional and urban air pollution problems, and the results would provide sound scientific basis for effective air quality management.

\section{Acknowledgments}

This research was supported by the Natural Sciences Foundation of China (no. 51038001) and the Ministry of Environmental Protection Special Funds for Scientific Research on Public Causes (no. 201209003). The authors would like to thank Natural Science Foundation of Beijing (no. 8092004), Beijing NOVA Program of China (no. 2009B07), Innovation Team Project of Beijing Municipal Education Commission (PHR201007105), and the Cultivation Fund of the Key Scientific and Technical Innovation Project, Ministry of Education of China (708017), for supporting this work.

\section{References}

[1] D. S. Chen, S. Y. Cheng, L. Liu, T. Chen, and X. R. Guo, "An integrated MM5-CMAQ modeling approach for assessing trans-boundary $\mathrm{PM}_{10}$ contribution to the host city of 2008 Olympic summer games-Beijing, China," Atmospheric Environment, vol. 41, no. 6, pp. 1237-1250, 2007. 
[2] D. S. Cohan, A. Hakami, Y. Hu, and A. G. Russell, "Nonlinear response of ozone to emissions: source apportionment and sensitivity analysis," Environmental Science and Technology, vol. 39, no. 17, pp. 6739-6748, 2005.

[3] F. Wang, D. S. Chen, S. Y. Cheng, and M. J. Li, "Impacts of air pollutant transport based on air trajectory clustering," Research of Environmental Sciences, vol. 22, no. 6, pp. 637-642, 2009 (Chinese).

[4] S. Cheng, D. Chen, J. Li, X. Guo, and H. Wang, "An ARPSCMAQ modeling approach for assessing the atmospheric assimilative capacity of the Beijing metropolitan region," Water, Air, and Soil Pollution, vol. 181, no. 1-4, pp. 211-224, 2007.

[5] S. M. Lee, H. J. S. Fernando, and S. Grossman-Clarke, "MM5SMOKE-CMAQ as a modeling tool for 8-h ozone regulatory enforcement: application to the state of Arizona," Environmental Modeling and Assessment, vol. 12, no. 1, pp. 63-74, 2007.

[6] Y. Zhou, S. Y. Cheng, L. Liu, and D. S. Chen, "A Coupled MM5CMAQ modeling system for assessing effects of restriction measures on $\mathrm{PM}_{10}$ pollution in Olympic city of Beijing, China," Journal of Environmental Informatics, vol. 19, no. 2, pp. 120-127, 2012.

[7] E. Angelino, M. Bedogni, C. Carnevale et al., " $\mathrm{PM}_{10}$ chemical model simulations over Northern Italy in the framework of the citydelta exercise," Environmental Modeling and Assessment, vol. 13, no. 3, pp. 401-413, 2008.

[8] U. Nopmongcol, B. Koo, E. Tai et al., "Modeling Europe with CAMx for the air quality model evaluation international initiative (AQMEII)," Atmospheric Environment, vol. 53, no. 7, pp. 177-185, 2012.

[9] J. Dudhia, D. Gill, K. Manning, W. Wang, and C. Bruyere, PSU/NCAR Mesoscale Modeling System Tutorial Class Notes and User's Guide: MM5 Modeling System Version 3, National Center for Atmospheric Research, 2004.

[10] X. Tie, S. Madronich, G. Li et al., "Characterizations of chemical oxidants in Mexico City: a regional chemical dynamical model (WRF-Chem) study," Atmospheric Environment, vol. 41, no. 9, pp. 1989-2008, 2007.

[11] S. Cheng, D. Chen, J. Li, H. Wang, and X. Guo, “The assessment of emission-source contributions to air quality by using a coupled MM5-ARPS-CMAQ modeling system: a case study in the Beijing metropolitan region, China," Environmental Modelling and Software, vol. 22, no. 11, pp. 1601-1616, 2007.

[12] M. Titov, A. P. Sturman, and P. Zawar-Reza, "Application of MM5 and CAMx4 to local scale dispersion of particulate matter for the city of Christchurch, New Zealand," Atmospheric Environment, vol. 41, no. 2, pp. 327-338, 2007.

[13] S. M. Lee, M. Princevac, S. Mitsutomi, and J. Cassmassi, "MM5 simulations for air quality modeling: an application to a coastal area with complex terrain," Atmospheric Environment, vol. 43, no. 2, pp. 447-457, 2009.

[14] H. Shimadera, A. Kondo, A. Kaga, K. L. Shrestha, and Y. Inoue, "Contribution of transboundary air pollution to ionic concentrations in fog in the Kinki Region of Japan," Atmospheric Environment, vol. 43, no. 37, pp. 5894-5907, 2009.

[15] C. Borrego, A. Monteiro, J. Ferreira et al., "Modelling the photochemical pollution over the metropolitan area of Porto Alegre, Brazil," Atmospheric Environment, vol. 44, no. 3, pp. 370-380, 2010.

[16] D. G. Streets, J. S. Fu, C. J. Jang et al., "Air quality during the 2008 Beijing Olympic Games," Atmospheric Environment, vol. 41, no. 3, pp. 480-492, 2007.

[17] Y. Zhou, S. Y. Cheng, J. B. Li, J. L. Lang, L. Li, and D. S. Chen, "A new statistical modeling and optimization framework for establishing high-resolution $\mathrm{PM}_{10}$ emission inventory-II. Integrated air quality simulation and optimization for performance improvement," Atmospheric Environment, vol. 60, pp. 623-631, 2012.

[18] Q. Huang, S. Y. Cheng, J. B. Li, D. S. Chen, H. Y. Wang, and X. R. Guo, "Assessment of $\mathrm{PM}_{10}$ emission sources for priority regulation in urban air quality management using a new coupled MM5-CAMx-PSAT modeling approach," Environmental Engineering Science, vol. 29, no. 5, pp. 343-349, 2012.

[19] A. M. Dunker, G. Yarwood, J. P. Ortmann, and G. M. Wilson, "Comparison of source apportionment and source sensitivity of ozone in a three-dimensional air quality model," Environmental Science and Technology, vol. 36, no. 13, pp. 2953-2964, 2002.

[20] K. M. Wagstrom, S. N. Pandis, G. Yarwood, G. M. Wilson, and R. E. Morris, "Development and application of a computationally efficient particulate matter apportionment algorithm in a three-dimensional chemical transport model," Atmospheric Environment, vol. 42, no. 22, pp. 5650-5659, 2008.

[21] B. Koo, G. M. Wilson, R. E. Morris, A. M. Dunker, and G. Yarwood, "Comparison of source apportionment and sensitivity analysis in a particulate matter air quality model," Environmental Science and Technology, vol. 43, no. 17, pp. 66696675, 2009.

[22] S. M. Almeida, C. A. Pio, M. C. Freitas, M. A. Reis, and M. A. Trancoso, "Source apportionment of fine and coarse particulate matter in a sub-urban area at the Western European Coast," Atmospheric Environment, vol. 39, no. 17, pp. 3127-3138, 2005.

[23] S. S. Park and Y. J. Kim, "Source contributions to fine particulate matter in an urban atmosphere," Chemosphere, vol. 59, no. 2, pp. 217-226, 2005.

[24] A. Srivastava, S. Gupta, and V. K. Jain, "Source apportionment of total suspended particulate matter in coarse and fine size ranges over Delhi," Aerosol and Air Quality Research, vol. 8, no. 2, pp. 188-200, 2008.

[25] Z. H. Chen, S. Y. Cheng, J. B. Li, X. R. Guo, W. H. Wang, and D. S. Chen, "Relationship between atmospheric pollution processes and synoptic pressure patterns in northern China," Atmospheric Environment, vol. 42, no. 24, pp. 6078-6087, 2008.

[26] F. Wang, D. S. Chen, S. Y. Cheng, J. B. Li, M. J. Li, and Z. $\mathrm{H}$. Ren, "Identification of regional atmospheric $\mathrm{PM}_{10}$ transport pathways using HYSPLIT, MM5-CMAQ and synoptic pressure pattern analysis," Environmental Modelling and Software, vol. 25, no. 8, pp. 927-934, 2010.

[27] Q. Zhang and D. G. Streets, "2006 Asia Emissions for INTEX-B," December 2009, http://www.cgrer.uiowa.edu/EMISSION_DATA_new/index_16.html.

[28] M. Viana, X. Querol, A. Alastuey, J. I. Gil, and M. Menéndez, "Identification of PM sources by principal component analysis (PCA) coupled with wind direction data," Chemosphere, vol. 65, no. 11, pp. 2411-2418, 2006.

[29] M. Statheropoulos, N. Vassiliadis, and A. Pappa, "Principal component and canonical correlation analysis for examining air pollution and meteorological data," Atmospheric Environment, vol. 32, no. 6, pp. 1087-1095, 1998.

[30] V. Isakov, A. Venkatram, J. S. Touma, D. Koračin, and T. L. Otte, "Evaluating the use of outputs from comprehensive meteorological models in air quality modeling applications," Atmospheric Environment, vol. 41, no. 8, pp. 1689-1705, 2007.

[31] S. A. Abdul-Wahab, C. S. Bakheit, and S. M. Al-Alawi, "Principal component and multiple regression analysis in modelling of ground-level ozone and factors affecting its concentrations," Environmental Modelling and Software, vol. 20, no. 10, pp. 12631271, 2005. 


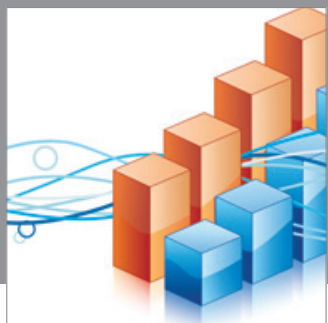

Advances in

Operations Research

mansans

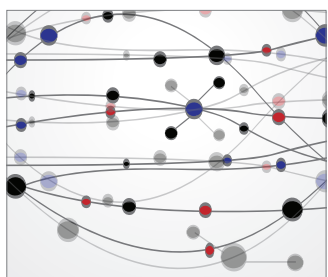

The Scientific World Journal
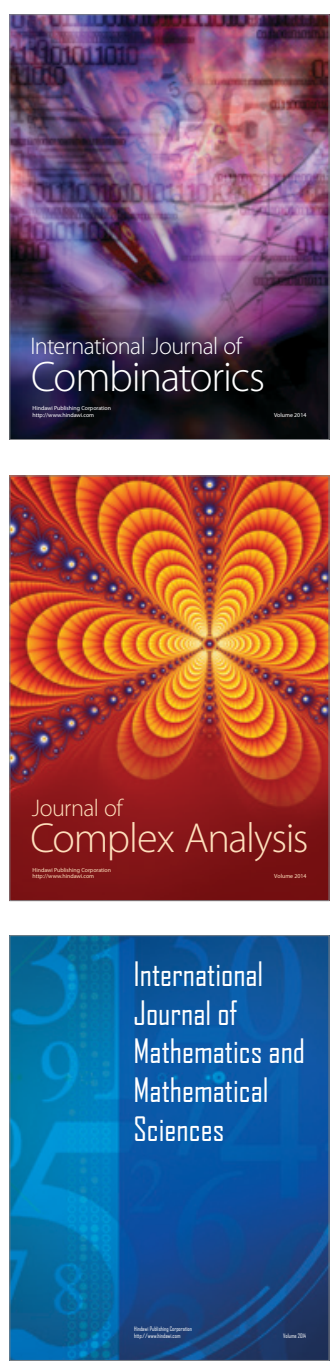
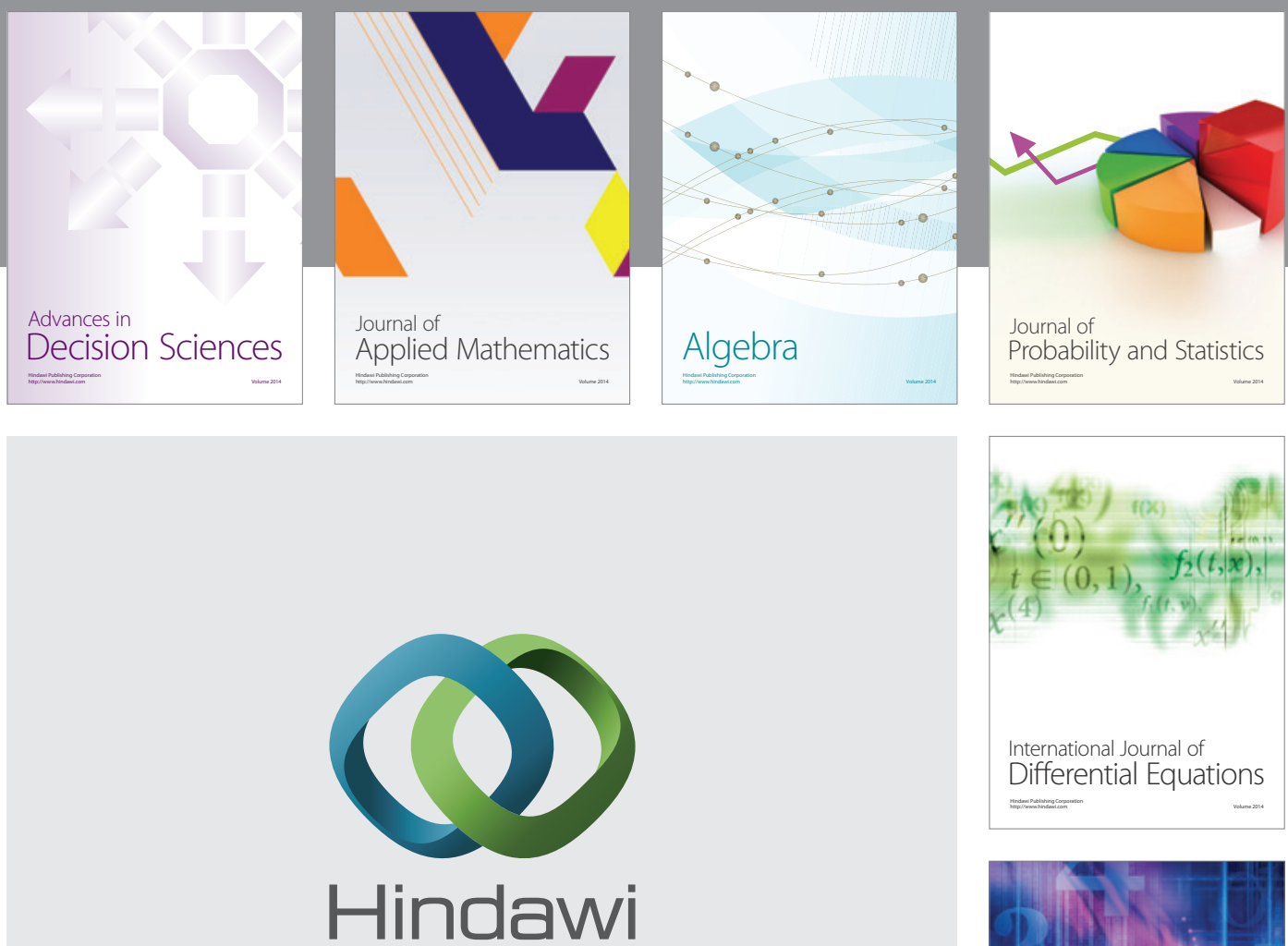

Submit your manuscripts at http://www.hindawi.com
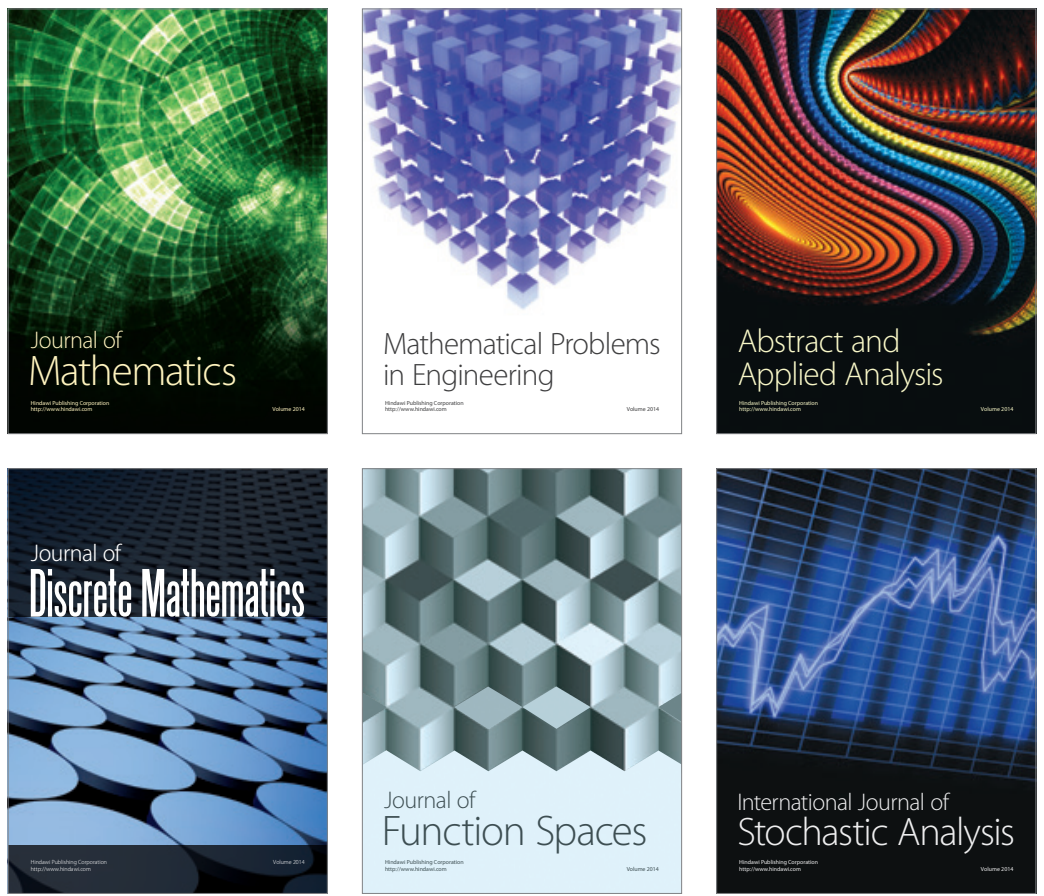

Journal of

Function Spaces

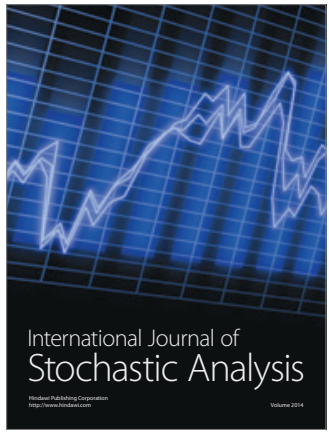

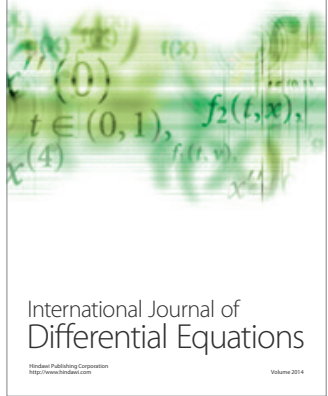
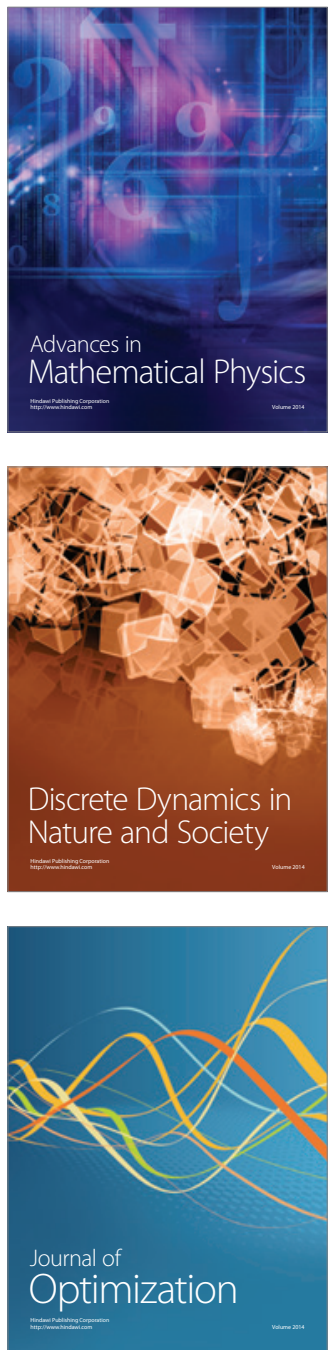